\title{
Adenosine-induced cardiac arrest as an alternative to temporary clipping during intracranial aneurysm surgery
}

\author{
Patcharin Intarakhao, MD, 1,2 Peeraphong Thiarawat, MD,,3 Behnam Rezai Jahromi, MB,1 \\ Danil A. Kozyrev, MD, ${ }^{1}$ Mario K. Teo, MD, FRCS(SN), ${ }^{4}$ Joham Choque-Velasquez, MD, ${ }^{1}$ \\ Teemu Luostarinen, MD, PhD, ${ }^{5}$ and Juha Hernesniemi, MD, PhD ${ }^{1}$
}

\begin{abstract}
${ }^{1}$ Department of Neurosurgery, Helsinki University Hospital, Helsinki, Finland; Departments of ${ }^{2}$ Anesthesiology and ${ }^{3}$ Surgery, Naresuan University, Phitsanulok, Thailand; ${ }^{4}$ Department of Neurosurgery, Bristol Institute of Clinical Neuroscience, North Bristol University Hospital, Bristol, United Kingdom; and ${ }^{5}$ Department of Anesthesiology, Intensive Care, Emergency Care and Pain Clinic, University of Helsinki and Helsinki University Hospital, Helsinki, Finland
\end{abstract}

OBJECTIVE The purpose of this study was to analyze the impact of adenosine-induced cardiac arrest (AiCA) on temporary clipping (TC) and the postoperative cerebral infarction rate among patients undergoing intracranial aneurysm surgery.

METHODS In this retrospective matched-cohort study, 65 patients who received adenosine for decompression of aneurysms during microsurgical clipping were identified (Group A) and randomly matched with 65 selected patients who underwent clipping but did not receive adenosine during surgery (Group B). The matching criteria included age, Fisher grade, aneurysm size, rupture status, and location of aneurysms. The primary outcomes were TC time and the postoperative infarction rate. The secondary outcome was the incidence of intraoperative aneurysm rupture (IAR).

RESULTS In Group A, 40 patients underwent clipping with AiCA alone and 25 patients (38\%) received AiCA combined with TC, and in Group B, 60 patients (92\%) underwent aneurysm clipping under the protection of TC $(0 R$ 0.052; $95 \% \mathrm{Cl}$ $0.018-0.147 ; p<0.001)$. Group A required less TC time $(2.04$ minutes vs 4.46 minutes; $p<0.001)$. The incidence of postoperative lacunar infarction was equal in both groups (6.2\%). There was an insignificant between-group difference in the incidence of IAR (1.5\% in Group A vs 6.1\% in Group B; OR 0.238; 95\% Cl 0.026-2.192; p = 0.171).

CONCLUSIONS AiCA is a useful technique for microneurosurgical treatment of cerebral aneurysms. AiCA can minimize the use of TC and does not increase the risk of IAR and postoperative infarction.

https://thejns.org/doi/abs/10.3171/2017.5.JNS162469

KEY WORDS adenosine-induced cardiac arrest; temporary clipping; postoperative lacunar infarction; intracranial aneurysm surgery; vascular disorders

$\mathrm{D}$ URING cerebral aneurysm clipping, a common technique for reducing intraaneurysmal pressure and preventing premature aneurysm rupture is temporary clipping (TC) of the feeding arteries. However, its use has some limitations such as timing-related cerebral ischemia, thromboembolic stroke, and vessel injury, especially in atherosclerotic vessels. TC is not feasible in some circumstances: for example, when treating a large or deepseated aneurysm for which visualization of the proximal artery is difficult or impossible. Accordingly, adenosineinduced cardiac arrest (AiCA) has slowly gained interest as an alternative option for the decompression of an aneurysm in such situations prior to permanent clip application.

Several studies have determined the safety of AiCA on perioperative and immediate postoperative outcome. ${ }^{3,4,16}$ However, the impact of AiCA on the use of TC, intraoperative aneurysm rupture (IAR), and radiographic outcome remains unclear.

The aims of the study were to compare the TC time, postoperative cerebral infarction rate, and IAR rate between patients treated with and without AiCA during intracranial aneurysm surgery.

ABBREVIATIONS ACA = anterior cerebral artery; $\mathrm{AiCA}=$ adenosine-induced cardiac arrest; $I \mathrm{AR}=$ intraoperative aneurysm rupture; $\mathrm{ICA}=$ internal carotid artery; $\mathrm{MCA}=$ middle cerebral artery; TC = temporary clipping.

SUBMITTED September 27, 2016. ACCEPTED May 8, 2017

INCLUDE WHEN CITING Published online October 27, 2017; DOI: 10.3171/2017.5.JNS162469. 


\section{Methods}

\section{Patients and Radiological Data}

A retrospective matched-cohort study was conducted. There were 250 cases of AiCA among 568 patients who underwent microsurgical clipping between 2005 and May 2013 in the Helsinki University Hospital medication database. For the purposes of this study and to review the full-length microsurgery intraoperative videos, we had to limit the cohort to patients treated after August 2010. The cases of all patients $(n=80)$ who received adenosine during microsurgical clipping between August 2010 and May 2013 were analyzed. This study was approved by the local university hospital's ethics committee.

After excluding 15 patients who underwent AiCA to control bleeding from IAR, the remaining 65 patients who received adenosine as an alternative to TC were included (Group A). For the control group, we randomly selected another 65 patients who underwent primary microsurgical clipping over the same study period (Group B). Our matching criteria included age, aneurysm location, size, rupture status, and Fisher grade at presentation. For matching purposes, patients in Group A were classified by aneurysm location into 4 groups-internal carotid artery (ICA), anterior cerebral artery (ACA), middle cerebral artery (MCA), or posterior circulation-and further classified as having ruptured or unruptured aneurysms. We tried to matched the number of aneurysms in each location and the characteristics of Group A to Group B. Our final study population consisted of 130 patients with a total of 130 aneurysms.

\section{Radiological Characterization}

All radiological images and official reports were available from the hospital's digital archiving system (IMPAX version 6.5.5.1608; Agfa). The diameters of the aneurysm dome and neck and the aneurysm maximal diameter were recorded. The presence of calcified ICA was also recorded to determine if it is a predictor of using adenosine for atherosclerotic ICA. Brain MRI was performed on patients with suspected postoperative stroke, otherwise all the patients would have undergone routine postoperative CT and CT angiography to exclude postoperative hematoma and assess the parent vessels after clip reconstruction.

\section{Operative Data and Outcome}

We evaluated overall TC time, number of TC episodes per case, average TC time per episode, and longest TC time per episode in both groups. We then determined the occurrence of IAR, particularly while deploying TC. In Group A, the reason for adenosine application was reviewed as well.

Impact on radiological outcome was evaluated by using immediate and delayed postoperative CT to determine postoperative cerebral infarction. We classified postoperative infarction into 2 categories: 1) infarction along the parent vessel territories; or 2) lacunar infarction characterized by a focal hypodense area in a perforator territory adjacent to the feeding vessels.

\section{Statistical Analysis}

We estimated that a total of 100 patients would be required to have an $80 \%$ chance of detecting a betweengroup difference in TC time greater than 120 seconds at a 5\% level of significance. We report normally distributed data as the mean $\pm \mathrm{SD}$ or median (range) and categorical data as the frequency and percentage. The differences between groups were assessed by the chi-square test and unpaired 2-tailed t-test. Statistical significance was set at $\mathrm{p}$ $<0.05$, and all statistical analyses were carried out using IBM SPSS Statistics for Macintosh (version 24.0).

\section{Results}

\section{Patients and Aneurysms}

There were 65 patients in each group. The mean age was $55 \pm 13.1$ years (range 21-79 years) in Group A and $59 \pm 11.6$ years (range 28-89 years) in Group B. The demographic data and radiological characteristics are summarized in Table 1 . There were no significant differences between the groups in age, Fisher grade at presentation, median aneurysm size, rupture status, aneurysm location, or calcification in the ICA. Group A consisted of 29 ICA aneurysms, 16 posterior circulation aneurysms, 14 ACA aneurysms, and 6 MCA aneurysms. Of the 29 ICA aneurysms, 20 aneurysms were ophthalmic aneurysms, 8 were posterior communicating artery aneurysms, and 1 was an ICA bifurcation aneurysm.

In Group A, 68\% of aneurysms (44 of 65) were unruptured. Of 44 patients with unruptured aneurysms, 35 (80\%) patients underwent clipping under AiCA alone compared with only 5 of 21 patients (24\%) with ruptured aneurysms that were clipped under AiCA alone (OR 12.444; 95\% CI 3.591-43.131; $\mathrm{p}<0.001)$.

Of the 65 aneurysms in Group A, 46 (70\%) were treated between 2012 and 2013, while 24 (37\%) were treated over the same period as Group B.

\section{Reason for Adenosine Use}

The main reason for adenosine administration was to avoid extensive bone drilling for proximal vessel exposure for TC $(41.5 \%)$, particularly for ICA aneurysms (66.7\%). Furthermore, we used adenosine in patients with an atherosclerotic ICA, a factor clearly associated with the presence of a calcified ICA on radiography (OR 5.7; 95\% CI 1.00532.904; $p=0.029$ ). We used AiCA in the contralateral approach, which is difficult to achieve proximal control. For ACA aneurysms, the vast majority of AiCA procedures were used to minimize aneurysm dissection. For large anterior communicating artery aneurysms, we administered adenosine in addition to using TC. Only 6 patients with MCA aneurysm received adenosine, and the main reason was to minimize feeding vessels and aneurysm dissection. In 16 patients with posterior circulation aneurysms, we administered adenosine to avoid extensive bone work for TC in 6 cases (38\%), instead of TC in 5 cases (31\%), and because the aneurysm was small in 4 cases (25\%) (Table 2).

\section{Dosage of Adenosine and Cardiac Complications}

Among 65 patients, 36 patients (55\%) received a single 
TABLE 1. Demographic data of 130 patients who underwent intracranial aneurysm surgery

\begin{tabular}{lccc}
\hline \multicolumn{1}{c}{ Variable } & Group A & Group B & p Value \\
\hline No. of aneurysms & 65 & 65 & \\
\hline Age, mean \pm SD, yrs & $55 \pm 13.1$ & $59 \pm 11.6$ & 0.064 \\
\hline $\begin{array}{l}\text { Aneurysm size, median } \\
\text { (range), mm }\end{array}$ & $4.8(1.8-19.2)$ & $5.5(2.0-29.0)$ & 0.292 \\
\hline Aneurysm size, no. (\%) & & & \\
\hline Small (<7 mm) & $47(72.3)$ & $44(67.7)$ & \\
\hline Medium (7-14 mm) & $14(21.5)$ & $17(26.2)$ & \\
\hline Large (15-24 mm) & $4(6.2)$ & $3(4.6)$ & \\
\hline Giant ( $\geq 25 \mathrm{~mm})$ & $0(0)$ & $1(1.5)$ & \\
\hline Rupture, no. (\%) & $21(32)$ & $23(35)$ & 0.339 \\
\hline Fisher grade, no. & & & 0.788 \\
\hline 1 & 1 & 0 & \\
\hline 2 & 1 & 2 & \\
\hline 3 & 11 & 9 & \\
\hline 4 & 10 & 12 & \\
\hline Aneurysm location, no. & & & \\
\hline ICA & 29 & 29 & \\
\hline ACA & 14 & 14 & \\
\hline MCA & 6 & 10 & \\
\hline Posterior circulation & 16 & 12 & \\
\hline Calcified ICA, no. (\%) & $18(27.7)$ & & \\
\hline & & & \\
\hline
\end{tabular}

adenosine bolus, whereas 29 patients received multiple boluses. The median dose for a single bolus was $30 \mathrm{mg}$ (range $5-50 \mathrm{mg}$ ). The median total dose of multiple boluses was $90 \mathrm{mg}$ (range 30-470 mg). The median number of boluses was 2 (range 2-10). Only 1 patient who received four 25-mg boluses of adenosine had atrial fibrillation. One patient who received $470 \mathrm{mg}$ of adenosine in 7 boluses had prolonged hypotension. No instances of postoperative myocardial infarction were observed in these patients, although during admission 7 patients were found to have raised cardiac troponin $\mathrm{T}$ levels due to subarachnoid hemorrhage.

\section{Impact on TC and IAR}

AiCA significantly minimized the use of TC. In 40 Group A patients, clipping was performed with AiCA alone and in 25 (38\%) clipping was performed in combination with TC compared with 60 patients (92\%) in Group $\mathrm{B}$ in whom TC was used (OR 0.052; 95\% CI 0.018-0.147; $\mathrm{p}<0.001)$.

In Group A, IAR occurred in 1 patient (1.5\%) compared with 4 patients $(6.1 \%)$ in Group B, even though this difference was not statistically significant (OR 0.238 ; $95 \%$ CI 0.026-2.192; $\mathrm{p}=0.171$ ). In both groups, no instance of IAR occurred during the deployment of a pilot clip.

There were significant differences in TC time between the 2 groups. Group A required a shorter mean total TC time (2.04 vs 4.46 minutes; $\mathrm{p}<0.001)$, lower mean time per episode (1.10 vs 3.07 minutes; $p=0.001$ ), and fewer TC episodes per case $(\mathrm{p}<0.001)$. The difference between
TABLE 2. Reasons for AiCA-associated intracranial aneurysm surgery by location in Group $A$

\begin{tabular}{|c|c|c|c|c|c|}
\hline \multirow[b]{2}{*}{$\begin{array}{l}\text { Reason for } \\
\text { AiCA }\end{array}$} & \multicolumn{5}{|c|}{ Aneurysm Location } \\
\hline & ICA & $\mathrm{ACA}$ & MCA & $\begin{array}{l}\text { Posterior } \\
\text { Circulation }\end{array}$ & Total \\
\hline No. of patients & $29(44.6)$ & $14(21.5)$ & $6(9.3)$ & $16(24.6)$ & \\
\hline $\begin{array}{l}\text { Avoid extensive } \\
\text { bone work } \\
\text { for TC }\end{array}$ & 18 & 2 & 1 & 6 & $27(41.5)$ \\
\hline Instead of TC & 2 & 3 & 1 & 5 & $11(17.0)$ \\
\hline Atherosclerosis & 5 & 0 & 1 & 0 & $6(9.2)$ \\
\hline Small aneurysm & 0 & 1 & 1 & 4 & $6(9.2)$ \\
\hline $\begin{array}{l}\text { Minimize dis- } \\
\text { section }\end{array}$ & 0 & 5 & 2 & 0 & $7(10.8)$ \\
\hline $\begin{array}{c}\text { Contralateral } \\
\text { approach }\end{array}$ & 2 & 0 & 0 & 0 & $2(3.1)$ \\
\hline $\begin{array}{l}\text { Supplement } \\
\text { to TC }\end{array}$ & 2 & 3 & 0 & 1 & $6(9.2)$ \\
\hline
\end{tabular}

Values indicate the number (\%) of patients.

the longest mean TC time per episode was also statistically significant (1.27 minutes for Group A vs 3.33 minutes for Group B; $p<0.001)$.

\section{Postoperative Radiological Outcome}

The postoperative infarction rate (lacunar infarction, parent vessel thrombosis, or both) was not significantly different between the 2 groups. Postoperative lacunar infarction occurred in 4 patients $(6.2 \%)$ in both groups (p $=1.0)$. In Group B, 1 patient $(1.5 \%)$ had postoperative infarction along the parent vessel territory compared with 2 patients (3\%) in Group A (p = 0.559) (Table 3).

\section{Discussion}

Several studies have shown the successful use of AiCA during intracranial aneurysm surgery. This technique was primarily used to control bleeding due to IAR. Recently, this strategy was also used as an adjunct to treat large, deeply located, and complex aneurysms without IAR.., 5 , ${ }_{11-13,18,20,21} \mathrm{AiCA}$ is relatively safe, and the literature shows that it has not been associated with perioperative cardiac morbidity., ${ }^{3,5,16,24,25}$ Bebawy et al. showed that AiCA was not associated with poor neurological outcome assessed using the modified Rankin Scale score as an indicator. ${ }^{4}$

To the best of our knowledge, our study is the first to compare the impact of AiCA on surgical technique during aneurysm surgery. We also compared TC time, incidence of IAR, and radiological outcome using the postoperative cerebral infarction rate between the 2 cohorts.

The majority of patients in Group B were operated on before 2012, whereas the majority of patients in Group A were operated on after 2012. This is probably because we have increasingly used AiCA as an alternative to TC since 2012. Since 2003, AiCA has been used during IAR at our institution, but the concept of using AiCA as an alternative to TC was developed in 2006 for complex an- 
TABLE 3. TC time, occurrence of intraoperative aneurysm rupture, and postoperative cerebral infarction

\begin{tabular}{lccccc}
\hline \multicolumn{1}{c}{ Variable } & Group A & Group B & $\mathrm{p} \mathrm{Value}$ & Odds Ratio & $95 \% \mathrm{Cl}$ \\
\hline No. of intraop ruptures & $1(1.5)$ & $4(6.1)$ & 0.171 & 0.238 & $0.026-2.192$ \\
\hline No. of TCs & $25(38)$ & $60(92)$ & $<0.001$ & 0.052 & $0.018-0.147$ \\
\hline No. of aneurysm ruptures during pilot clip deployment & 0 & 0 & 1.0 & $\mathrm{NA}$ & $\mathrm{NA}$ \\
\hline Mean total TC time, mins & $2.04 \pm 0.27(0-18.22)$ & $4.46 \pm 0.35(0-22.46)$ & $<0.001$ & $\mathrm{NA}$ & $\mathrm{NA}$ \\
\hline Mean no. of TC episodes & $0.74 \pm 0.14$ & $1.63 \pm 0.14$ & $<0.001$ & $\mathrm{NA}$ & $\mathrm{NA}$ \\
\hline Mean TC time per episode, mins & $1.10 \pm 0.13(0-7.50)$ & $3.07 \pm 0.30(0-22.46)$ & 0.001 & $\mathrm{NA}$ & $\mathrm{NA}$ \\
\hline Mean longest TC time per episode, mins & $1.27 \pm 0.19(0-13.45)$ & $3.33 \pm 0.31(0-22.46)$ & 0.001 & $\mathrm{NA}$ & $\mathrm{NA}$ \\
\hline No. of postop lacunar infarctions & $4(6.15)$ & $4(6.15)$ & 1.0 & 1.0 & $0.239-4.181$ \\
\hline No. of postop infarctions along parent vessel territory & $2(3)$ & $1(1.5)$ & 0.559 & 2.032 & $0.180-22.975$ \\
\hline
\end{tabular}

$\mathrm{NA}=$ not applicable

Values represent the number (\%) or the mean \pm SD (range) unless otherwise specified.

eurysm clipping (ophthalmic artery aneurysms and basilar artery aneurysms). Since 2012, we have expanded the use of AiCA as an alternative for TC to other aneurysms. The decision to choose TC or AiCA is mostly preplanned based on evaluation of the preoperative images. However, the strategy can be changed according to intraoperative findings.

Our results demonstrated that we prefer to use adenosine for small and unruptured aneurysms, as these aneurysms can usually be visualized in their entirety. Thus, these aneurysms can be clipped with low risk of IAR without TC, but with AiCA, in our experience.

This study also indicated a higher propensity to use adenosine for paraclinoid aneurysms and posterior circulation aneurysms because proximal control is difficult to achieve and extensive bone work is usually required to expose the parent vessel for TC. The clipping of ophthalmic artery aneurysms frequently requires anterior clinoidectomy to achieve proximal control. In our practice, tailored anterior clinoidectomy is preferably done by removing the necessary amount of bone that provides just enough space for the proximal blade of the clip. ${ }^{28,32}$ Using AiCA com- bined with tailored anterior clinoidectomy can simplify the surgery and help prevent unnecessary bone work (Fig. 1). Likewise, proximal control of basilar artery bifurcation aneurysms that are below the sellar floor through the subtemporal approach might require the additional removal of the petrosal apex. ${ }^{2,15,33}$ This surgical procedure requires extensive bone work and prolongs the operative time. With AiCA, we can clip basilar artery bifurcation aneurysms as soon as we identify the aneurysm neck without the need to identify the basilar artery (Fig. 2).

Clipping a posterior circulation aneurysm is technically challenging due to the narrow operative corridor. To achieve proximal and distal control of these aneurysms, extensive microsurgical dissection would be required, which might risk perforator injuries, and TC might obscure the direction of pilot clipping. Therefore, small posterior circulation aneurysms, when the aneurysm's dome and neck can be visualized well, could be clipped with AiCA and this might lower the risk of IAR.

TC is useful for decompressing the aneurysm sac, and a temporary arterial occlusive time as long as 15-20 minutes is considered safe. . $8,9,14,17,19,22,23,30,31$ However, some
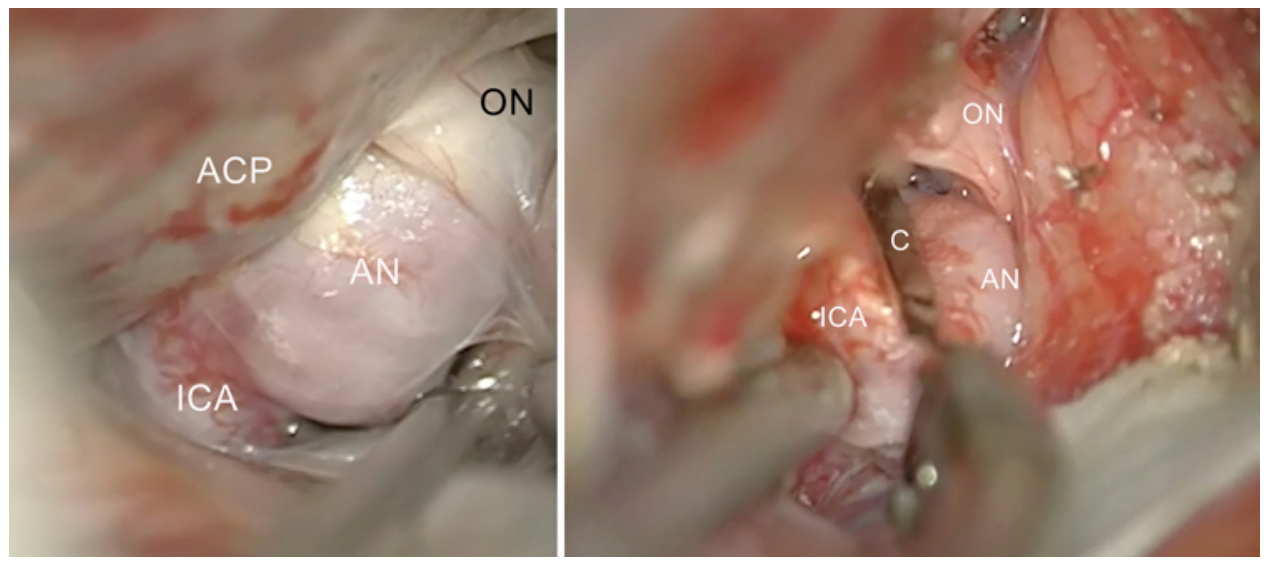

FIG. 1. Intraoperative photographs of a left ophthalmic artery aneurysm via the left lateral supraorbital approach. Left: The proximal aneurysm neck is obscured by the anterior clinoid process. Right: After tailored anterior clinoidectomy, there is sufficient space for the proximal blade of the clip but insufficient space for the proximal TC. ACP = anterior clinoid process; $A N=$ aneurysm; $\mathrm{C}=$ proximal blade of the clip; $\mathrm{ON}=$ optic nerve. 


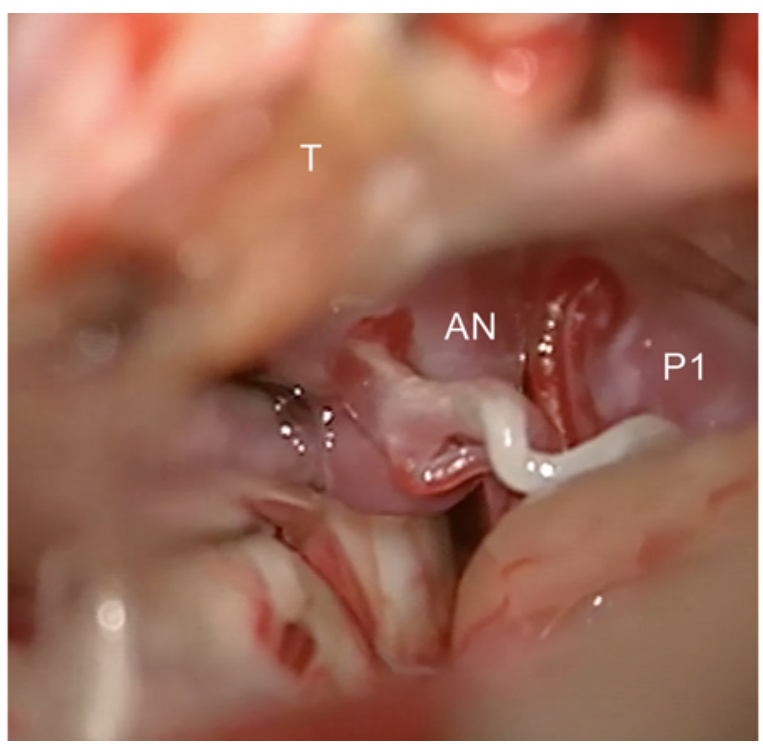

FIG. 2. Intraoperative photograph of a basilar artery bifurcation aneurysm via the left subtemporal approach. The neck of the aneurysm and the posterior cerebral artery can be identified, but the basilar artery is obscured by the tentorial edge. $\mathrm{P} 1=$ posterior cerebral artery; $\mathrm{T}=$ tentorial cerebelli.

reports have found an association between poor neurological outcome and the use of TC. ${ }^{4}$ Therefore, we try to minimize the use of TC by using AiCA instead-for example, when clip adjustment is needed or TC obscures the direction of final clip application.

Moreover, this study showed an additional indication for the use of AiCA. For patients with ICA aneurysms, the presence of calcified ICA on preoperative CT angiography deters us from applying TC to the parent vessel. We prefer intraoperative adenosine because TC of the atherosclerotic vessel might cause atherosclerotic plaque rupture and result in thromboembolic events.

For most complex aneurysms, coordinated use of AiCA with TC provides further aneurysm sac decompression. We use AiCA to minimize surgical dissection in some situations. For example, our technique for clipping an MCA bifurcation aneurysm is focused opening of the sylvian fissure.? This technique allows a narrower clipping field than a wide sylvian opening. Once the clipping field is prepared, the aneurysm's neck is identified, as well as the frontal and temporal branches of the insular segment of MCA $\left(\mathrm{M}_{2}\right)$, and the aneurysm can be clipped under AiCA without proximal control. Exposing the sphenoidal segment of MCA $\left(\mathrm{M}_{1}\right)$ to achieve proximal control requires further sylvian dissection, which potentially increases the risk for iatrogenic brain injury. Likewise, we can use AiCA to clip a pericallosal artery aneurysm when dissection toward the proximal pericallosal artery is difficult.

The drawback of using the contralateral approach to clip a contralateral ICA aneurysm is the deep and narrow surgical corridor (Fig. 3). Moreover, the contralateral optic nerve obscures the proximal ICA, resulting in difficult TC. Andrade-Barazarte et al. reported our institution's

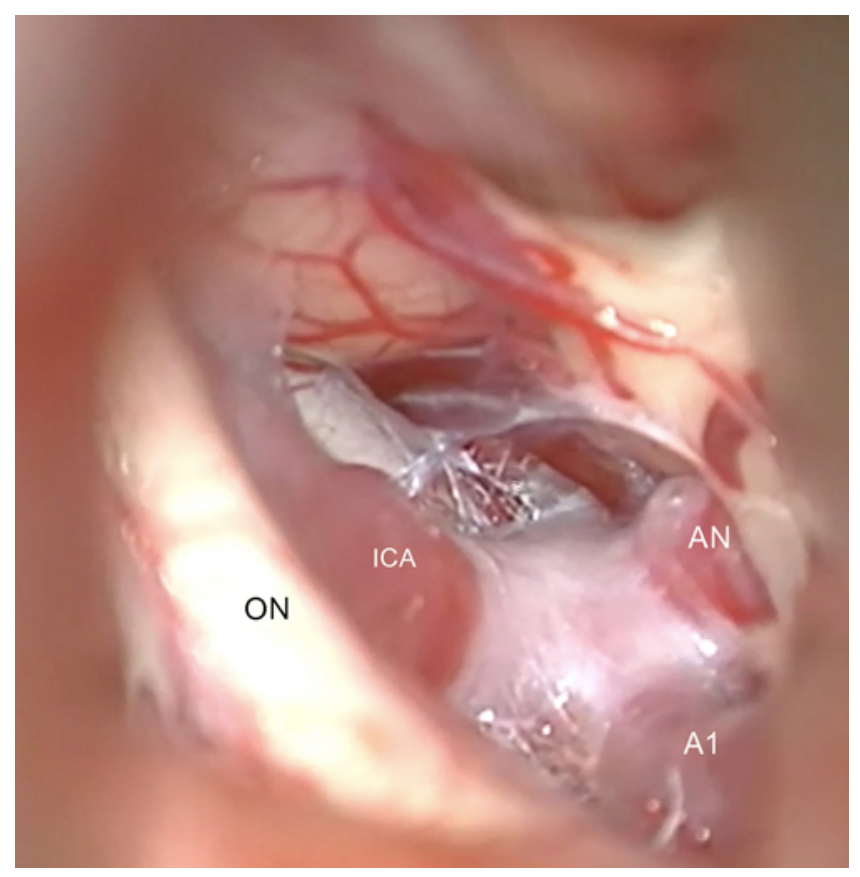

FIG. 3. Intraoperative photograph of a contralateral ICA bifurcation aneurysm through the contralateral approach (left lateral supraorbital approach). Note that the contralateral ICA is obscured by the contralateral optic nerve. $A 1=A 1$ segment of the contralateral $A C A$.

experience of using AiCA in the contralateral approach as an alternative to TC and achieving good postoperative outcomes. ${ }^{1}$

Our results emphasize the safety of AiCA because cardiac complications are infrequent and self-limiting. Atrial fibrillation and prolonged hypotension were also reported in previous studies with a relatively low incidence and resolved spontaneously. ${ }^{3,5,16,27}$ The duration of hypotension that occurs subsequent to transient systole might be associated with the dose of adenosine.

The current study indicated a lower IAR rate for Group A (1.5\%) compared with Group B (6.1\%), although the difference was not statistically significant. Moreover, AiCA can minimize the use of TC, total TC time per case, and temporary occlusive episodes, as well as the longest TC time per episode.

Posterior circulation aneurysms are associated with worsened neurological outcome after aneurysm surgery. ${ }^{9,10,26,29}$ Our results revealed low postoperative infarction rates in both study groups, even though the study population had a higher ratio of posterior circulation aneurysms. In 3 cases $(2 \%)$ in the entire series, iatrogenic occlusion of the parent vessel or prolonged TC time could have been responsible for postoperative infarction along the parent vessel territory. We also noted that cerebral vasospasm was likely responsible for postoperative lacunar infarction, as these patients are more likely to present with aneurysmal subarachnoid hemorrhage.

\section{Limitations}

This was a retrospective study, and therefore the exact 
reasons for using AiCA during surgery might have varied, and in some cases there could have been multiple reasons to use AiCA.

\section{Conclusions}

AiCA is extremely helpful as an addition or alternative to TC. AiCA can facilitate microneurosurgical dissection, minimize the use of TC, and help with aneurysm clipping. We also found that AiCA does not increase the risk of IAR and postoperative infarction.

\section{References}

1. Andrade-Barazarte H, Luostarinen T, Goehre F, Kivelev J, Jahromi BR, Ludtka C, et al: Transient cardiac arrest induced by adenosine: a tool for contralateral clipping of internal carotid artery-ophthalmic segment aneurysms. World Neurosurg 84:1933-1940, 2015

2. Aziz KM, Tew JM Jr, Chicoine MR: The Kawase approach to retrosellar and upper clival basilar aneurysms. Neurosurgery 44:1225-1236, 1999

3. Bebawy JF, Gupta DK, Bendok BR, Hemmer LB, Zeeni C, Avram MJ, et al: Adenosine-induced flow arrest to facilitate intracranial aneurysm clip ligation: dose-response data and safety profile. Anesth Analg 110:1406-1411, 2010

4. Bebawy JF, Zeeni C, Sharma S, Kim ES, DeWood MS, Hemmer LB, et al: Adenosine-induced flow arrest to facilitate intracranial aneurysm clip ligation does not worsen neurologic outcome. Anesth Analg 117:1205-1210, 2013

5. Bendok BR, Gupta DK, Rahme RJ, Eddleman CS, Adel JG, Sherma AK, et al: Adenosine for temporary flow arrest during intracranial aneurysm surgery: a single-center retrospective review. Neurosurgery 69:815-821, 2011

6. Charbel FT, Ausman JI, Diaz FG, Malik GM, Dujovny M, Sanders J: Temporary clipping in aneurysm surgery: technique and results. Surg Neurol 36:83-90, 1991

7. Elsharkawy A, Niemelä M, Lehečka M, Lehto H, Jahromi BR, Goehre F, et al: Focused opening of the sylvian fissure for microsurgical management of MCA aneurysms. Acta Neurochir (Wien) 156:17-25, 2014

8. Ferch R, Pasqualin A, Pinna G, Chioffi F, Bricolo A: Temporary arterial occlusion in the repair of ruptured intracranial aneurysms: an analysis of risk factors for stroke. J Neurosurg 97:836-842, 2002

9. Griessenauer CJ, Poston TL, Shoja MM, Mortazavi MM, Falola M, Tubbs RS, et al: The impact of temporary artery occlusion during intracranial aneurysm surgery on long-term clinical outcome: part I. Patients with subarachnoid hemorrhage. World Neurosurg 82:140-148, 2014

10. Griessenauer CJ, Poston TL, Shoja MM, Mortazavi MM, Falola M, Tubbs RS, et al: The impact of temporary artery occlusion during intracranial aneurysm surgery on long-term clinical outcome: part II. The patient who undergoes elective clipping. World Neurosurg 82:402-408, 2014

11. Groff MW, Adams DC, Kahn RA, Kumbar UM, Yang BY, Bederson JB: Adenosine-induced transient asystole for management of a basilar artery aneurysm. Case report. J Neurosurg 91:687-690, 1999

12. Guinn NR, McDonagh DL, Borel CO, Wright DR, Zomorodi AR, Powers CJ, et al: Adenosine-induced transient asystole for intracranial aneurysm surgery: a retrospective review. J Neurosurg Anesthesiol 23:35-40, 2011

13. Heppner PA, Ellegala DB, Robertson N, Nemergut E, Jaganathan J, Mee E: Basilar tip aneurysm - adenosine induced asystole for the treatment of a basilar tip aneurysm following failure of temporary clipping. Acta Neurochir (Wien) 149:517-521, 2007
14. Jabre A, Symon L: Temporary vascular occlusion during aneurysm surgery. Surg Neurol 27:47-63, 1987

15. Kawase T, Toya S, Shiobara R, Mine T: Transpetrosal approach for aneurysms of the lower basilar artery. J Neurosurg 63:857-861, 1985

16. Khan SA, McDonagh DL, Adogwa O, Gokhale S, Toche UN, Verla T, et al: Perioperative cardiac complications and 30-day mortality in patients undergoing intracranial aneurysmal surgery with adenosine-induced flow arrest: a retrospective comparative study. Neurosurgery 74:267-272, 2014

17. Lavine SD, Masri LS, Levy ML, Giannotta SL: Temporary occlusion of the middle cerebral artery in intracranial aneurysm surgery: time limitation and advantage of brain protection. J Neurosurg 87:817-824, 1997

18. Lee SH, Kwun BD, Kim JU, Choi JH, Ahn JS, Park W, et al: Adenosine-induced transient asystole during intracranial aneurysm surgery: indications, dosing, efficacy, and risks. Acta Neurochir (Wien) 157:1879-1886, 2015

19. Ljunggren B, Säveland H, Brandt L, Kågström E, Rehncrona $\mathrm{S}$, Nilsson PE: Temporary clipping during early operation for ruptured aneurysm: preliminary report. Neurosurgery 12:525-530, 1983

20. Luostarinen T, Takala RS, Niemi TT, Katila AJ, Niemela M, Hernesniemi J, et al: Adenosine-induced cardiac arrest during intraoperative cerebral aneurysm rupture. World Neurosurg 73:79-83, e79, 2010

21. Nussbaum ES, Sebring LA, Ostanny I, Nelson WB: Transient cardiac standstill induced by adenosine in the management of intraoperative aneurysmal rupture: technical case report. Neurosurgery 47:240-243, 2000

22. Ogawa A, Sato H, Sakurai Y, Yoshimoto T: Limitation of temporary vascular occlusion during aneurysm surgery. Study by intraoperative monitoring of cortical blood flow. Surg Neurol 36:453-457, 1991

23. Ogilvy CS, Carter BS, Kaplan S, Rich C, Crowell RM: Temporary vessel occlusion for aneurysm surgery: risk factors for stroke in patients protected by induced hypothermia and hypertension and intravenous mannitol administration. J Neurosurg 84:785-791, 1996

24. Owall A, Gordon E, Lagerkranser M, Lindquist C, Rudehill A, Sollevi A: Clinical experience with adenosine for controlled hypotension during cerebral aneurysm surgery. Anesth Analg 66:229-234, 1987

25. Owall A, Lagerkranser M, Sollevi A: Effects of adenosineinduced hypotension on myocardial hemodynamics and metabolism during cerebral aneurysm surgery. Anesth Analg 67:228-232, 1988

26. Raaymakers TW, Rinkel GJ, Limburg M, Algra A: Mortality and morbidity of surgery for unruptured intracranial aneurysms: a meta-analysis. Stroke 29:1531-1538, 1998

27. Rangel-Castilla L, Russin JJ, Britz GW, Spetzler RF: Update on transient cardiac standstill in cerebrovascular surgery. Neurosurg Rev 38:595-602, 2015

28. Romani R, Elsharkawy A, Laakso A, Kangasniemi M, Hernesniemi J: Tailored anterior clinoidectomy through the lateral supraorbital approach: experience with 82 consecutive patients. World Neurosurg 77:512-517, 2012

29. Rosengart AJ, Schultheiss KE, Tolentino J, Macdonald RL: Prognostic factors for outcome in patients with aneurysmal subarachnoid hemorrhage. Stroke 38:2315-2321, 2007

30. Samson D, Batjer HH, Bowman G, Mootz L, Krippner WJ $\mathrm{Jr}$, Meyer YJ, et al: A clinical study of the parameters and effects of temporary arterial occlusion in the management of intracranial aneurysms. Neurosurgery 34:22-29, 1994

31. Suzuki J, Kwak R, Okudaira Y: The safe time limit of temporary clamping of cerebral arteries in the direct surgical treatment of intracranial aneurysm under moderate hypothermia. Tohoku J Exp Med 127:1-7, 1979

32. Thiarawat P, Jahromi BR, Kozyrev DA, Intarakhao P, Teo 
MK, Choque-Velasquez J, et al: microneurosurgical management of posterior communicating artery aneurysm: a contemporary series from Helsinki. World Neurosurg 101:379-388, 2017

33. Tjahjadi M, Kivelev J, Serrone JC, Maekawa H, Kerro O, Jahromi BR, et al: Factors determining surgical approaches to basilar bifurcation aneurysms and its surgical outcomes. Neurosurgery 78:181-191, 2016

\section{Disclosures}

The authors report no conflict of interest concerning the materials or methods used in this study or the findings specified in this paper.

\section{Author Contributions}

Conception and design: Intarakhao. Acquisition of data: Intarakhao, Thiarawat, Kozyrev. Analysis and interpretation of data: Thiarawat. Drafting the article: Intarakhao, Thiarawat, Kozyrev. Critically revising the article: Rezai Jahromi, Kozyrev, Teo, Luostarinen. Reviewed submitted version of manuscript: Intarakhao, Thiarawat, Rezai Jahromi, Teo, Hernesniemi. Approved the final version of the manuscript on behalf of all authors: Intarakhao. Statistical analysis: Thiarawat. Administrative/technical/material support: Rezai Jahromi, Choque-Velasquez. Study supervision: Luostarinen, Hernesniemi.

\section{Correspondence}

Patcharin Intarakhao, Department of Anesthesiology, Naresuan University, 99 Moo 9 Tambon Tha Pho, Muang Phitsanulok, Phitsanulok, Thailand 65000. email: patcharin_int@hotmail.com. 